\title{
Negatively charged silver nanoparticles with potent antibacterial activity and reduced toxicity for pharmaceutical preparations
}

This article was published in the following Dove Press journal:

International Journal of Nanomedicine

31 March 2017

Number of times this article has been viewed

\author{
Lucia Salvioni' \\ Elisabetta Galbiati' \\ Veronica Collico' \\ Giulia Alessio' \\ Svetlana Avvakumova' \\ Fabio Corsi ${ }^{2,3}$ \\ Paolo Tortora' \\ Davide Prosperi' \\ Miriam Colombo' \\ 'Nanobiolab, Department of \\ Biotechnology and Bioscience, \\ University of Milano-Bicocca, \\ ${ }^{2}$ Biological and Clinical Science \\ Department, University of Milan, \\ Milano, ${ }^{3}$ Surgery Department, Breast \\ Unit, IRCCS S Maugeri Foundation, \\ Pavia, Italy
}

Background: The discovery of new solutions with antibacterial activity as efficient and safe alternatives to common preservatives (such as parabens) and to combat emerging infections and drug-resistant bacterial pathogens is highly expected in cosmetics and pharmaceutics. Colloidal silver nanoparticles (NPs) are attracting interest as novel effective antimicrobial agents for the prevention of several infectious diseases.

Methods: Water-soluble, negatively charged silver nanoparticles (AgNPs) were synthesized by reduction with citric and tannic acid and characterized by transmission electron microscopy, dynamic light scattering, zeta potential, differential centrifuge sedimentation, and ultravioletvisible spectroscopy. AgNPs were tested with model Gram-negative and Gram-positive bacteria in comparison to two different kinds of commercially available AgNPs.

Results: In this work, AgNPs with higher antibacterial activity compared to the commercially available colloidal silver solutions were prepared and investigated. Bacteria were plated and the antibacterial activity was tested at the same concentration of silver ions in all samples. The AgNPs did not show any significant reduction in the antibacterial activity for an acceptable time period. In addition, AgNPs were transferred to organic phase and retained their antibacterial efficacy in both aqueous and nonaqueous media and exhibited no toxicity in eukaryotic cells. Conclusion: We developed AgNPs with a $20 \mathrm{~nm}$ diameter and negative zeta potential with powerful antibacterial activity and low toxicity compared to currently available colloidal silver, suitable for cosmetic preservatives and pharmaceutical preparations administrable to humans and/or animals as needed.

Keywords: silver nanoparticles, antibacterial activity, long-term effect, nanoparticle toxicity, phase transfer

\section{Introduction}

The discovery and introduction of antibiotics was one of the greatest conquests in the history of medicine considerably contributing to improve the average life expectancy of the world population. ${ }^{1}$ However, the increasing misuse and abuse of antibacterial agents has led to resistance and cross-resistance. Indeed, most pathogenic bacteria become resistant with time to the action of antibiotics. ${ }^{2,3}$ This effect represents a paramount medical problem so that new molecules and compounds with high and persistent antibacterial activity are required to face the challenge of emerging infections and the global spread of drug-resistant microbial pathogens. ${ }^{4}$

In addition to the treatment of infections, novel preservatives are essential in pharmaceutical and cosmetic areas as an alternative solution to the widely used esters of $p$-hydroxybenzoic acid (parabens). ${ }^{5}$ Despite their potent antimicrobial action, parabens
Correspondence: Davide Prosperi; Miriam Colombo

Department of Biotechnology and Bioscience, University of Milano-Bicocca, Piazza della Scienza 2, 20126 Milano, Italy Tel +390264483388

Fax +390264483565

Email davide.prosperi@unimib.it; miriam.colombo@unimib.it 
are known to bind to human estrogen receptors, although with lower affinity compared to estradiol, potentially leading to undesired side effects, including acting as promoters of breast cancer. ${ }^{6,7}$ For these reasons, the use of nontraditional antibacterial compounds is assuming increasing relevance. ${ }^{8}$ Taking advantage of the bacteria sensitivity to silver ions, ${ }^{9}$ colloidal silver nanoparticles (CSNPs) have emerged as a novel class of potential antimicrobial agents for the treatment of different infectious diseases, including antibiotic-resistant pathogens, and have been assessed in vitro as well as in animal. ${ }^{10}$

Due to its unique chemical properties, silver is broadly utilized in several different fields, for example, optics and photonics, electron microscopy, catalysis, and biology; silver is found in everyday products such as computers, cell phones, vacuum cleaners, filters for water and air, textile products, and due to the antibacterial and antimicrobial properties, also in deodorants, soaps, toothbrushes, and toothpaste. ${ }^{11}$ Silver, in the form of silver ions or nanoparticles (NPs), has been used for centuries against various diseases and, in particular, for its strong antiseptic and antimicrobial efficacy against both Gram-positive and Gram-negative bacteria associated with low toxicity. Although the antimicrobial mechanism of action of silver ions has not been fully elucidated yet and remains controversial, evidence of their activity in the inhibition of the enzyme respiratory system, in the alteration of the microbial DNA, and in the cell wall degradation has been provided. ${ }^{12}$ Moreover, silver nanoparticles (AgNPs) exhibit a broad spectrum of actions against morphologically and metabolically different microorganisms. ${ }^{13}$ The differences in using AgNPs and silver ions as salts are essentially associated to a unique character of the NPs in biological systems, which allows us to assume the occurrence of effective interactions with bacterial membranes and sustained intracellular release of silver ions. In particular, the chemical-physical properties of AgNPs allow for their interaction with the surface of the bacterial cell by altering the structure therein, thus favoring its permeability and subsequent cell death., ${ }^{4,13}$

To develop AgNPs as additives suitable to be included in the production of cosmetics or pharmaceutical formulations for the purpose of human care, we have selected a chemical synthetic approach for their preparation in different suspensions, including aqueous and oily solutions. In this article, we report the synthesis, characterization, cytotoxicity, and potent antibacterial activity of $20 \mathrm{~nm}$, negatively charged AgNPs in comparison with two different colloidal silver formulations from commercial sources.

\section{Materials and methods Materials}

Silver nitrate ( $\geq 99.0 \%$ ), tannic acid, sodium citrate (SC), octadecylamine, silver dispersion (SNPs, $40 \mathrm{~nm}$ particle size), and all organic solvents were purchased from SigmaAldrich (St Louis, MO, USA). All chemicals were used as received without further purification. Paraffin was obtained from Marco Viti (Mozzate, Italy). Colloidal NPs (CNPs) were purchased from Atena Srl (Toronto, Ontario, CA).

\section{AgNPs synthesis}

An aqueous solution $(100 \mathrm{~mL})$ containing $\mathrm{SC}(5 \mathrm{mM})$ and tannic acid $(0.025 \mathrm{mM})$ was prepared and heated to the boiling point. The solution was boiled for $15 \mathrm{~min}$, and then $1 \mathrm{~mL}$ of aqueous silver nitrate solution $(25 \mathrm{mM})$ was quickly added with a syringe under vigorous stirring (750 rpm). The solution became immediately yellow, and after $1 \mathrm{~h}$ heating, it was allowed to cool down and kept under stirring overnight at room temperature.

AgNPs formation was assessed using ultraviolet-visible (UV-vis) spectroscopy by the occurrence of the characteristic absorption peak corresponding to the plasmon resonance band. The resulting AgNPs were purified by centrifugation (two washes: $25,000 \times \mathrm{g}, 45 \mathrm{~min}, 4^{\circ} \mathrm{C}$ ) and further suspended in $1 \mathrm{mM} \mathrm{SC}$ solution or $0.3 \mathrm{mM}$ phosphate buffer (PB), $\mathrm{pH} 7.2$, depending on the use.

\section{NPs characterization}

\section{Dynamic light scattering and zeta potential}

The NPs hydrodynamic diameter and zeta potential were analyzed on a Zetasizer Nano ZS ZEN3600 from Malvern Instruments Ltd (Worcestershire, UK) operating at a light source wavelength of $633 \mathrm{~nm}$ and a fixed scattering angle of $173^{\circ}$. For dynamic light scattering (DLS) analysis, the purified samples were diluted three times both in SC $1 \mathrm{mM}$ and in $0.3 \mathrm{mM} \mathrm{PB}, \mathrm{pH}$ 7.2. For zeta potential, the samples were diluted in $0.3 \mathrm{mM} \mathrm{PB}, \mathrm{pH}$ 7.2. The results were expressed as mean \pm standard deviation (SD) of three measurements.

\section{Transmission electron microscopy}

NPs were visualized using an FEI $120 \mathrm{KV}$ Tecnai G2 spirit Bio TWIN Instrument. The sample $(2 \mu \mathrm{L})$ was deposited onto a formvar-coated 200-mesh copper grid (Ted Pella, Redding, CA, USA), and allowed to dry in air before examination. For the mean diameter determination of NPs, images were processed with ImageJ software. The reported value was calculated measuring at least 100 particles. 


\section{UV-vis spectroscopy}

UV-vis spectra were recorded using a Nanodrop 2000c spectrophotometer from Thermo Scientific (Wilmington, NC, USA). Before measurement, all samples were diluted three times in $1 \mathrm{mM} \mathrm{SC}$ and in $0.3 \mathrm{mM} \mathrm{PB}, \mathrm{pH}$ 7.2.

\section{Differential centrifuge sedimentation analysis}

Particle size distribution was measured using a CPS disc centrifuge DC24000 (CPS Instruments Inc.). A gradient fluid, 8-24 wt \% sucrose solution in Milli-Q water, was freshly prepared and filled successively in nine steps into the disc, rotating at a speed of $24,000 \mathrm{rpm}$, starting with the solution of the highest density. Calibration was performed using poly(vinyl chloride) particles $(0.239 \mu \mathrm{m}$, Analytik, Ltd) as a calibration standard before each measurement.

\section{Silver content quantification}

The total silver content in each kind of NP sample was determined by inductively coupled plasma optical emission spectrometry (ICP-OES). For this purpose, $3 \mathrm{~mL}$ of aqua regia were added to $200 \mu \mathrm{L}$ of each sample and, after $72 \mathrm{~h}$ digestion, the samples were diluted with $7 \mathrm{~mL}$ of distilled water. All samples were measured in triplicate with the Optima 7000 DV ICP-OES.

\section{Stability test}

AgNPs stability $\left(4^{\circ} \mathrm{C}, 6\right.$ months) was assessed in $1 \mathrm{mM} \mathrm{SC}$ and in $0.3 \mathrm{mM} \mathrm{PB}, \mathrm{pH} 7.2$, using UV-vis spectroscopy. Absorption spectra were detected and reported in the supporting information along with maximum absorbance as a function of time.

\section{Lyophilization}

NPs suspension in $1 \mathrm{mM} \mathrm{SC}$ was dried by lyophilization using a Christ Alpha 1-2 D freeze dryer from Martin Christ Gefriertrocknungsanlagen GmbH (Osterode an Harz, Germany). NPs were characterized as described above.

\section{Antibacterial activities test}

Antibacterial activity of NPs suspensions was tested on Gram-negative (Escherichia coli MG1665) and Grampositive (Staphylococcus aureus) bacteria. A typical procedure was as follows: bacterial cultures were grown overnight into an Erlenmeyer flask containing nutrient broth (Bactotryptone $10 \% \mathrm{w} / \mathrm{V}$, yeast extract $5 \%, \mathrm{NaCl} 5 \%$ ), then the suspension was diluted at an initial optical density of 0.05 at $600 \mathrm{~nm}$ $\left(\mathrm{OD}_{600 \mathrm{~nm}}\right)$ and cultures were allowed to grow at $37^{\circ} \mathrm{C}$ under stirring $(160 \mathrm{rpm})$. When the cultures reached an $\mathrm{OD}_{600 \mathrm{~nm}}$ of 0.65 ( $\sim 10^{8}$ colony forming units $\left.(\mathrm{CFU}) / \mathrm{mL}\right), 1 \mathrm{~mL}$ was withdrawn, centrifuged $\left(2,000 \times g, 15 \mathrm{~min}, 25^{\circ} \mathrm{C}\right)$, and washed twice with $0.3 \mathrm{mM} \mathrm{PB}, \mathrm{pH}$ 7.2. Following washing, the cells were suspended and diluted in PB containing AgNPs or other antibacterial agents to get a final bacterial concentration of $2 \times 10^{5} \mathrm{CFU} / \mathrm{mL}$. Untreated samples, diluted in PB, were used as control. Bacterial suspensions were incubated on a rotary shaker at $130 \mathrm{rpm}, 37^{\circ} \mathrm{C}$ for $2 \mathrm{~h}$. Thereafter, $100 \mu \mathrm{L}$ of decimal dilution (10- and $10^{2}$-fold) were plated onto Nutrient Agar plates. Following incubation $\left(12 \mathrm{~h}\right.$ at $\left.37^{\circ} \mathrm{C}\right)$, the plates were counted for viable bacteria. The survival rate was calculated according to the equation:

$$
\text { Fold-logarithmic reduction }=\log \mathrm{N}_{\text {untreated }} / \mathrm{N}_{\text {treated }}
$$

where $\mathrm{N}_{\text {untreated }}$ is the number of $\mathrm{CFU} / \mathrm{mL}$ in the control and $\mathrm{N}_{\text {treated }}$ is the number of CFU/mL in the samples following exposure to an antibacterial agent. Each experiment was performed in triplicates.

To compare their efficacy, different antibacterial agents were tested at the same silver content: $0.54 \mathrm{ng} / \mathrm{mL}$ for $E$. coli and $5.4 \mathrm{ng} / \mathrm{mL}$ for $S$. aureus, respectively.

\section{Long-term antibacterial activity}

The experiment was performed as describe above. In this case, $2 \times 10^{5}$ cells were incubated with antibacterial agents ( $0.54 \mathrm{ng} / \mathrm{mL}$ silver content) for $2,4,6$, and $24 \mathrm{~h}$. After the incubation time, $2 \times 10^{2}$ theoretical cells number of each samples were plated on a solid growth medium and were incubated overnight at $37^{\circ} \mathrm{C}$ in duplicate. Grown CFU were counted and the results expressed as follows:

$$
\text { Inibition effect }(\%)=\mathrm{N}_{\text {untreated }} / \mathrm{N}_{\text {treated }} \times 100
$$

The antibacterial activity was evaluated only for $E$. coli because $S$. aureus did not show survival at long incubation time.

\section{Phase transfer}

Octadecylamine solution in ethanol $(10 \mathrm{~mL}, 20 \mathrm{mM})$ was added while stirring ( $500 \mathrm{rpm}$ ) to $10 \mathrm{~mL}$ of unpurified AgNPs solution obtained as described above. After $5 \mathrm{~min}$, toluene $(10 \mathrm{~mL})$ was added to the mixture and left under stirring for 10 minutes. The AgNPs were transferred into the organic phase. No NPs were then recovered both in the aqueous phase and at the interphase. The solvent was evaporated and the product was dispersed in 
ethanol. To remove the excess alkylamine, the resultant AgNPs were purified by centrifugation (two washes, $3,500 \times \mathrm{g}, 15 \mathrm{~min}$, at $4^{\circ} \mathrm{C}$ ). After solvent evaporation, the AgNPs were suspended in tetrahydrofuran (THF) or an oily solution (eg, peanut oil) depending on the use.

\section{Scanning and transmission electron microscopy analyses}

Bacterial suspension was prepared as described in the antibacterial activity test section. When the suspension reached an $\mathrm{OD}_{600 \mathrm{~nm}}$ of $0.65,15 \mathrm{~mL}$ were withdrawn, centrifuged $\left(2,000 \times g, 15 \mathrm{~min}, 25^{\circ} \mathrm{C}\right)$, and washed twice with $0.3 \mathrm{mM} \mathrm{PB}$, $\mathrm{pH}$ 7.2. Following washing, $10^{8}$ cells were resuspended in $30-\mathrm{mL}$ buffer containing (treated) or not containing (untreated) AgNPs at a final concentration of $0.54 \mu \mathrm{g} / \mathrm{mL}$ for $E$. coli and $5.4 \mu \mathrm{g} / \mathrm{mL}$ for $S$. aureus. The bacterial suspension was incubated on a rotary shaker at $130 \mathrm{rpm}, 37^{\circ} \mathrm{C}$, for $2 \mathrm{~h}$. After incubation, the cells were washed three times by centrifugation $(2,000 \times g, 7 \mathrm{~min})$ to separate the residual AgNPs. Next, each sample (both pellets and bacterial suspensions recovered after treatment) was dispersed in $1 \mathrm{~mL}$ of $2.5 \% \mathrm{w} / \mathrm{V}$ glutaraldehyde solution.

Transmission electron microscopy (TEM) samples were prepared as follows: the suspension was washed three times in PB and resuspended in double-distilled water. The sample $(2 \mu \mathrm{L})$ was deposited onto a formvar-coated 200-mesh copper grid (Ted Pella, Redding, CA, USA) and allowed to dry in air before examination. In case of cell pellets, after one rinsing with $\mathrm{PB}$, the specimens were postfixed in $1.5 \%$ osmium tetroxide for $2 \mathrm{~h}$, dehydrated by $70 \%, 90 \%$, and $100 \%$ ethanol, and embedded in epoxy resin (PolyBed 812 Polysciences Inc., Warminster, PA, USA). The ultrathin sections were stained with uranyl acetate and lead citrate and examined.

For SEM analysis, after washing, the bacterial suspensions were dehydrated by $70 \%, 90 \%$, and $100 \%$ ethanol and resuspended in hexamethyldisilazane. Several drops of the suspension were deposited on a glass slide, dried, and sputter-coated in a vacuum with an electrically conductive $5 \mathrm{~nm}$ thick layer of gold-palladium alloy. SEM images were then recorded with a SEM (Leica S420).

\section{MTT assay}

3T3-L1 murine fibroblasts were seeded on a 96-multiwell dish at a density of 5,000 cells $/ \mathrm{cm}^{2}$ and grown for $24 \mathrm{~h}$ in Dulbecco's Modified Eagle's Medium(DMEM, supplemented with $10 \%$ fetal bovine serum, $2 \mathrm{mM}$ L-glutamine, $50 \mathrm{UI} / \mathrm{mL}$ penicillin, and $50 \mathrm{mg} / \mathrm{mL}$ streptomycin). The cells were incubated with AgNPs at different concentrations (1 and
$10 \mathrm{ng} / \mathrm{mL})$. At the indicated time points $(24,48$, and $72 \mathrm{~h}$ ), the cells were washed with PBS and then incubated for $3 \mathrm{~h}$ at $37^{\circ} \mathrm{C}$ with $0.1 \mathrm{~mL}$ of 3-(4,5-dimethyl-2-thiazolyl)2,5-diphenyl-2H-tetrazolium bromide (MTT) stock solution previously diluted 1:10 in DMEM without phenol red. At the end of the incubation, $0.1 \mathrm{~mL}$ of MTT solubilizing solution was added to each well to solubilize the MTT formazan crystals (Sigma-Aldrich). Absorbances were read immediately in an UV-vis plate reader using a test wavelength of $570 \mathrm{~nm}$ and a reference wavelength of $620 \mathrm{~nm}$. The results were expressed as mean \pm standard deviation of an average of four individual experiments. The statistical significance was determined using one-way analysis of variance (ANOVA).

\section{Results and discussion Synthesis and characterization of AgNPs}

Long-term stable aqueous colloidal dispersions of AgNPs with narrow size distributions were synthesized according to Bastús et al, with some modifications. ${ }^{14}$ An aqueous silver nitrate solution was boiled in a reducing agent mixture containing SC and tannic acid. Upon silver addition, the solution immediately turned clear yellow due to the CNPs formation (Figure 1A).

The reaction was monitored by UV-vis spectroscopy. A peak $\sim 400 \mathrm{~nm}$ corresponding to the Ag surface plasmon resonance appeared associated to the formation of NPs (Figure 1A). The thin shape (full width athalfmaximum $=68 \mathrm{~nm}$ ) and peak symmetry reflected the AgNPs narrow distribution in terms of size and shape. The observed absorption $\lambda_{\text {max }}$ at $405 \mathrm{~nm}$ was in line with the NPs size expected from the results of the relevant TEM and DLS analyses. ${ }^{15,16}$ In addition, a great reproducibility intra-batches was observed confirming the method robustness (Table S1; Figures S1 and S2).

The size and net particle charge of the as-synthesized AgNPs were determined through different techniques. The AgNPs showed a mean effective diameter of $19.3 \pm 5.6 \mathrm{~nm}$ assessed by TEM (Figure 1C); a mean hydrodynamic size of $42.3 \pm 4.7 \mathrm{~nm}(\mathrm{PDI}=0.204$ ) evaluated by DLS (Figure 1B); and a centrifugal density size of $16.6 \pm 3.7 \mathrm{~nm}$ obtained by differential centrifugal sedimentation (DCS; Figure 1D). Although the size values derived from TEM and DCS were comparable, the significant difference observed by DLS might be due to a strong solvation effect. As expected, due to the presence of citrate as stabilizer, the AgNPs were negatively charged with a zeta potential of $-18.3 \pm 1.9 \mathrm{mV}$ calculated by electrophoretic mobility. The long-term stability of AgNPs was assessed by monitoring the NPs plasmon band position of AgNPs by UV-vis absorption spectroscopy. Either $1 \mathrm{mM}$ SC solution 


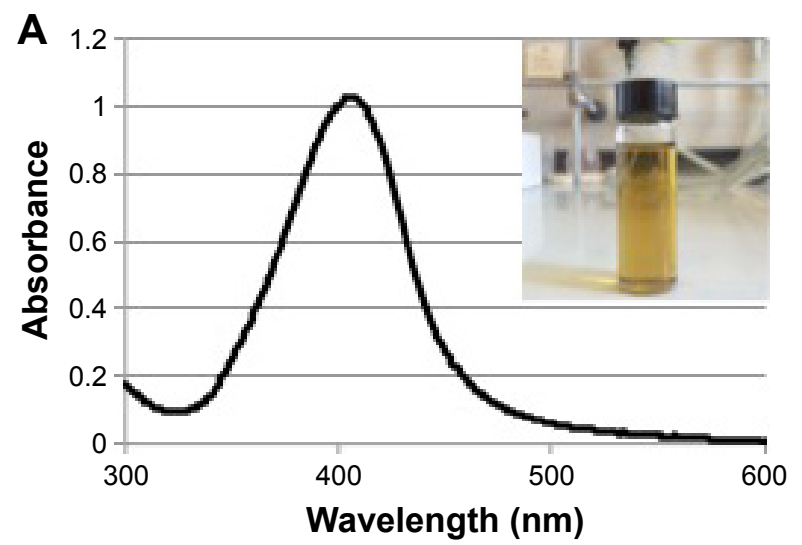

B

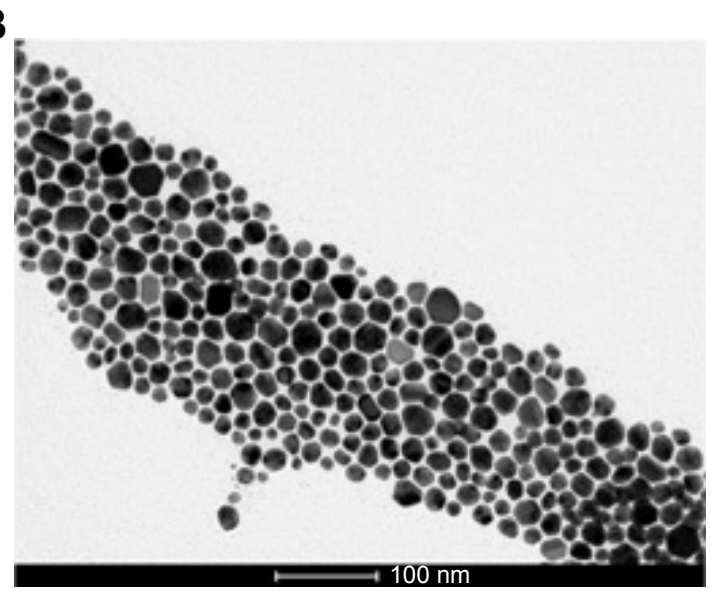

C

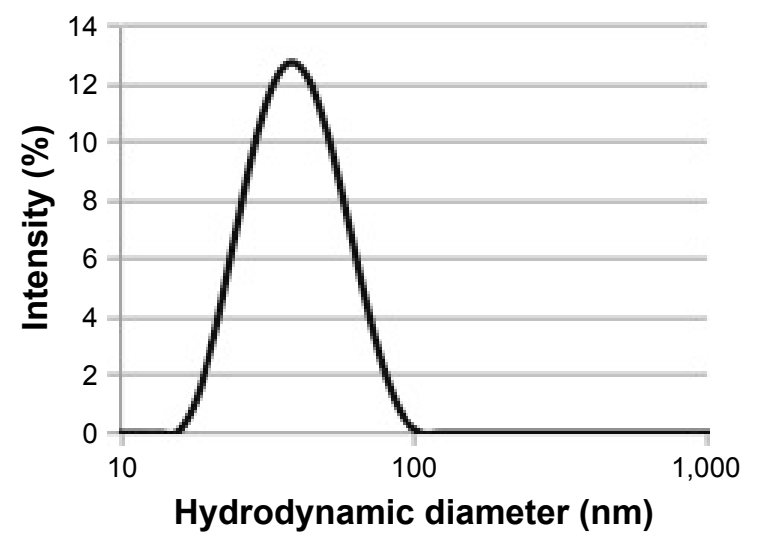

D

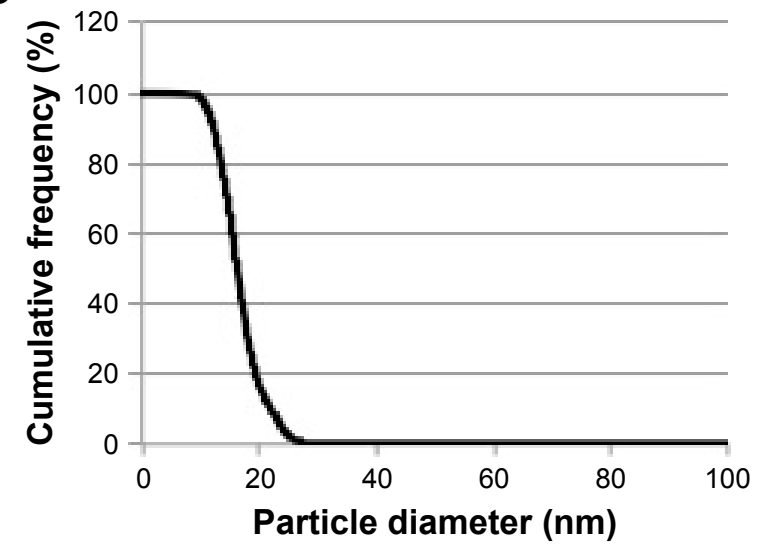

Figure I AgNPs characterization.

Notes: (A) Plasmon band position of AgNPs by UV-vis absorption spectroscopy and AgNPs colloidal solution (inset); (B) TEM image of AgNPs suspended in water, scale bar: $100 \mathrm{~nm}$. AgNPs size distribution evaluated by (C) DLS in I mM citrate and (D) DCS in a sucrose gradient.

Abbreviations: AgNPs, silver nanoparticles; DCS, differential centrifugal sedimentation; DLS, dynamic light scattering; TEM, transmission electron microscopy; UV-vis, ultraviolet-visible.

or $0.3 \mathrm{mM}$ PB, pH 7.2 was used to assess the reliability of the antibacterial test conditions. No degradation or aggregation was observed within 6 months of storage (Figure S3). Importantly, in view of a possible industrial production and purification, the integrity and colloidal stability of AgNPs was confirmed by evaluating the size of the NPs dispersion after lyophilization and resuspension (Figure S4). ${ }^{17}$

\section{Antibacterial activity of AgNPs against Gram-negative and Gram-positive bacteria}

The antimicrobial properties of AgNPs have demonstrated their broad spectra of activity against Gram-positive and Gram-negative bacteria, fungi, and viruses. ${ }^{18-21}$ To assess the properties of our AgNPs in comparison to other antibacterial products, we chose Gram-negative bacteria E. coli MG1665 and Gram-positive bacteria $S$. aureus.

About $2 \times 10^{5}$ cells were incubated with different concentrations of antibacterial agents for $2 \mathrm{~h}$. After the incubation time, $100 \mu \mathrm{L}$ of step-wise decimal dilutions up to $2 \times 10^{3}$ theoretical cells number were plated on a solid growth medium and incubated overnight at $37^{\circ} \mathrm{C}$.

The number of CFU grown on the plate was counted and the results expressed as difference in viability (logarithmicfold reduction) in comparison to the untreated control. Differently from conventional approaches that normally utilize the broth microdilution method to determine the minimal inhibitory concentration (MIC) for the determination of antimicrobial activity, ${ }^{22}$ the tests reported in this work were performed in plates because AgNPs were not stable in bacteria medium (Figure S5). In addition, we assessed the capability of AgNPs to kill the bacteria cells rather than evaluating the bacteriostatic power (MIC) of our preparations.

First, to evaluate AgNPs activity, different concentrations (from $10^{+2}$ to $10^{-2} \mathrm{ng} / \mathrm{mL}$ silver content) were tested (data not shown). To compare the antibacterial efficacy of AgNPs with that of the commercial products, concentrations showing a threefold logarithmic decrease in cells number were selected. 
Among commercially available NPs, we chose citratestabilized AgNPs synthesized in an aqueous solution with slightly higher average size (40 nm AgNPs from Sigma, SNPs) and CSNPs commercially available for medical uses with a diameter of a few nanometers (Figure S6). Their chemico-physical characteristics are summarized in Table 1. Moreover, we performed the antimicrobial experiments with an equal concentration of silver ions in the form of $\mathrm{AgNO}_{3}$ salt. The NP concentrations were evaluated by ICP-OES analysis measuring the amount of $\mathrm{Ag}$ ions in each sample.

The AgNPs prepared in the present work showed a superior antibacterial efficacy compared with the abovementioned commercial AgNPs (Figures 2 and 3).

Although the discussion in literature on the possible impact of NPs in the administration of silver is controversial, our results suggest a strong improvement in antibacterial activity using AgNPs compared to $\mathrm{Ag}^{+}$salts (Figures 2 and 3). A detailed elucidation of the antibacterial effect of $\mathrm{Ag}^{+}$ions is still lacking; however, we can speculate on two possible reasons supporting such a strong difference. First, although the $\mathrm{Ag}^{+}$ions uptake is normally controlled by the action of cationic pumps, AgNPs are able to be taken up by the cells exploiting nonspecific interactions, thus resulting in higher Ag content inside and/or across the cell wall. ${ }^{23-25}$ A second plausible explanation resides in the favorable redox potential of $\mathrm{Ag}^{0}$ atoms on the NP surface, which is expected to trigger the generation of large amounts of free radicals leading to cytotoxic reactive oxygen species production. $^{12,26-28}$

The low activity of SNPs compared to AgNPs can be explained in terms of different size: indeed, as expected, the $40 \mathrm{~nm}$-sized SNPs possess significantly lower surface area leading to both decreased interactions with bacteria and reduced release of $\mathrm{Ag}^{+}$ions. ${ }^{29} \mathrm{We}$ found high data variability using CSNPs. This is consistent with a low colloidal stability of the suspension attributable to a strongly elevated surface tension. Indeed, TEM analysis revealed that CSNPs were very small, that is, in the sub-5 $\mathrm{nm}$ range (Figure S6). Such a small size combined with their bare surface claimed in

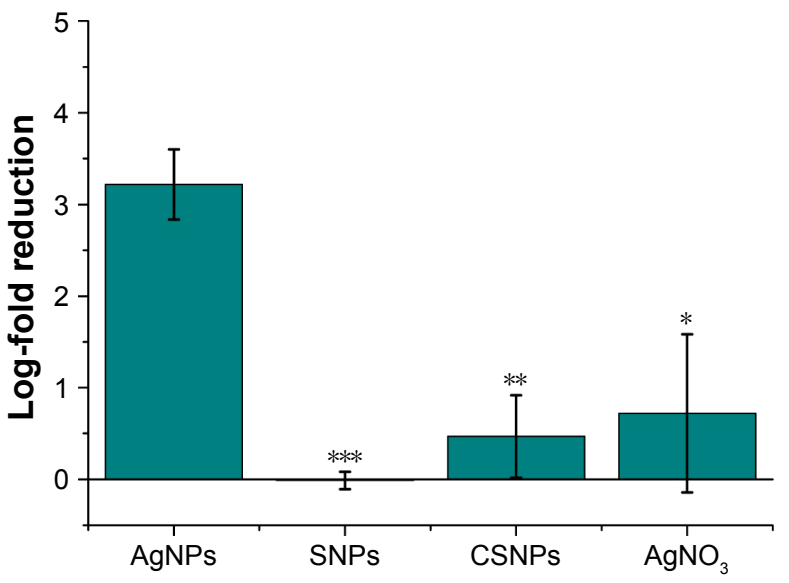

Figure 2 Antibacterial activity of AgNPs $(0.54 \mathrm{ng} / \mathrm{mL}$ silver content) in $E$. coli MGI665 after 2 h. Samples show statistical differences from AgNPs samples at $* * * P<0.0005$; ** $P<0.0$ I; $* P<0.05$.

Abbreviations: $\mathrm{AgNO}_{3}$, silver nitrate; AgNPs, silver nanoparticles; CSNPs, colloidal silver nanoparticles; E. coli, Escherichia coli; SNPs, silver nanoparticles.

product label results in a significantly reduced colloidal stability in biological media. In addition, the behavior of such small colloids is expected to be more similar to that of Ag ions than to larger NPs. Although CSNPs data were difficult to be interpreted due to such a low reproducibility, they suggested lower efficacy of CSNPs compared to AgNPs.

A further advance of our AgNPs relates to their negative surface charge, $-18.3 \pm 1.9 \mathrm{mV}$ as determined by zeta potential; most examples from the literature suggest that an essential condition to improve the antibacterial efficacy of AgNPs is to have a positive particle surface charge. In fact, the positive charge allows for more efficient electrostatic interaction with the negative charges of the bacterial cell wall. ${ }^{30}$ This expected effect obviously contrasted with our experimental data and represents a further important advantage of our antibacterial NPs in terms of safety in mammalian cells and tissues, assuming that cationic NPs are more cytotoxic than those with neutral or negative surface charge ${ }^{31}$ Altogether, these properties make AgNPs an optimal alternative to cosmetic and food preservatives. As expected, the NP concentration necessary to obtain the same amount of dead cells was 10-fold higher in the case of $S$. aureus (Figure 3) in comparison

Table I Nanoparticles characterization

\begin{tabular}{|c|c|c|c|c|c|c|}
\hline & $\begin{array}{l}\text { Effective diameter } \\
\text { (TEM analysis, } \mathrm{nm} \text { ) }\end{array}$ & PDI & $\begin{array}{l}\text { Hydrodynamic diameter } \\
\text { (DLS analysis, } \mathrm{nm} \text { ) }\end{array}$ & PDI & $\begin{array}{l}\zeta \text { potential } \\
(\mathrm{mV})\end{array}$ & $\begin{array}{l}\lambda_{\max } \text { ABS } \\
(\mathbf{n m})\end{array}$ \\
\hline CSNPs & $1.89 \pm 0.67$ & 0.126 & $177.3 \pm 12.16$ & 0.244 & $-17.8 \pm 0.802$ & - \\
\hline SNPs & $37.8 \pm 5.3$ & 0.020 & $72.56 \pm 0.647$ & 0.308 & $-36.6 \pm 0.643$ & 417 \\
\hline $\mathrm{AgNPs}$ & $19.3 \pm 5.6$ & 0.084 & $42.3 \pm 4.7$ & 0.203 & $-18.3 \pm 1.9$ & 405 \\
\hline
\end{tabular}

Abbreviations: AgNPs, silver nanoparticles; CSNPs, colloidal silver nanoparticles; SNPs, silver nanoparticles; DLS, dynamic light scattering; TEM, transmission electron microscopy. 


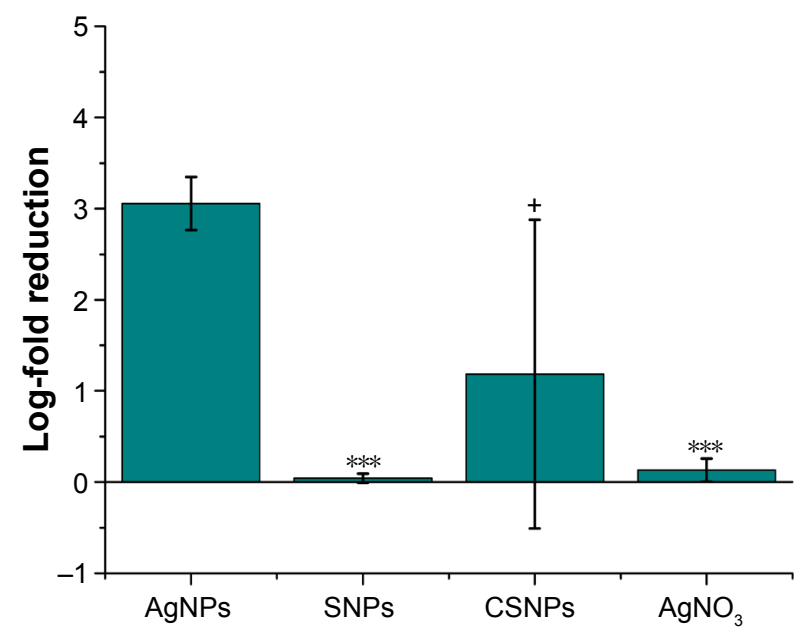

Figure 3 Antibacterial activity of AgNPs ( $5.4 \mathrm{ng} / \mathrm{mL}$ silver content) in S. aureus after $2 \mathrm{~h}$. Samples show statistical differences from AgNPs samples at $* * * P<0.0005$; $+P<0.2$.

Abbreviations: $\mathrm{AgNO}_{3}$, silver nitrate; AgNPs, silver nanoparticles; CSNPs, colloidal silver nanoparticles; S. aureus, Staphylococcus aureus; SNPs, silver nanoparticles.

with $E$. coli (Figure 2) because of the presence of a thicker peptidoglycan layer in their cell wall. ${ }^{32}$

\section{Long-term antibacterial activity of AgNPs against Gram-negative bacteria}

To evaluate the extent of the antimicrobial effect of AgNPs in comparison to CSNPs, the NPs were incubated with $2 \times 10^{5}$ $E$. coli cells for $2,4,6$, and $24 \mathrm{~h}$ with a NP concentration lower than the above experiments in order to evaluate the inhibition effect over time. After the incubation time, $2 \times 10^{2}$ theoretical cell numbers of each sample were plated on a solid growth medium and incubated overnight at $37^{\circ} \mathrm{C}$ in duplicate. The number of CFU grown on the plate was counted and the results expressed in percentage of the untreated control. As expected, smaller AgNPs (CSNPs) exhibited a significantly higher release rate and final ion concentration compared to larger ones (AgNPs), resulting in an improved long-lasting effect of AgNPs (Figure 4).

In contrast, no prolonged effect was observed with Grampositive bacteria due to a rapid and complete cell death already after $2 \mathrm{~h}$.

\section{AgNPs phase transfer in oil phase and antimicrobial properties maintenance}

AgNPs are intended to be developed for pharmaceutical and cosmetic preparations administrable to humans and/or animals in liquid, semisolid, and solid pharmaceutical formulations on the need. As commercial formulations are based on water-soluble, fat-soluble ingredients and their

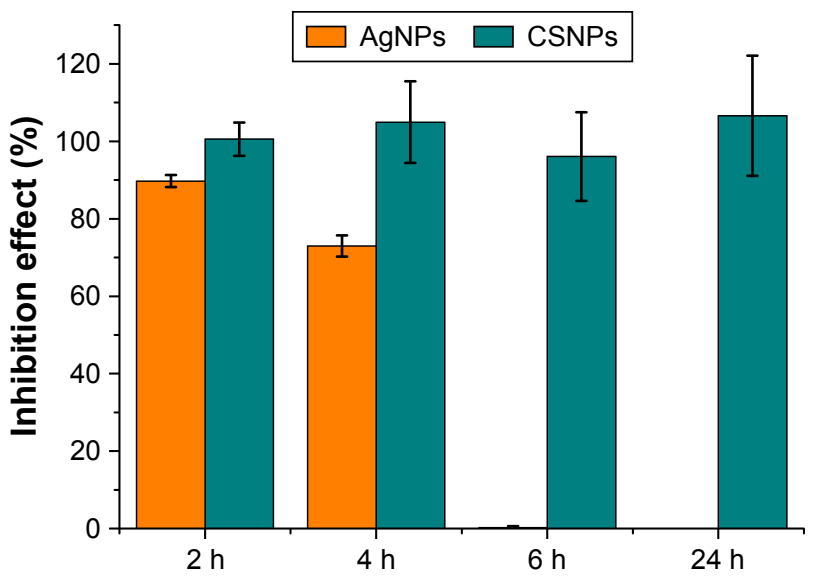

Figure 4 Long-term antibacterial activity of nanoparticles.

Note: AgNPs and CSNPs $(0.054 \mathrm{ng} / \mathrm{mL}$ silver content) were incubated with $E$. coli MGI 665 for 2, 4, 6, and $24 \mathrm{~h}$.

Abbreviations: AgNPs, silver nanoparticles; CSNPs, colloidal silver nanoparticles; E. coli, Escherichia coli.

combinations, a phase transfer approach was developed to allow AgNPs to be suspended not only in aqueous solution but also in oily mixtures. Hence, a protocol to transfer AgNPs from the aqueous to the organic/oily phase was developed using octadecylamine as a surfactant added to the NPs suspension. ${ }^{31}$

The product was, thus, suspended in peanut oil or paraffin. The solution was homogeneous and stable (Figure S7). Differently from other methods, the advantage of the reported phase transfer protocol consists in its good transfer efficiency independently on the volume and the number of NPs. ${ }^{31}$

Tests analog to those described above were carried out using AgNPs soluble in oil phase. THF was chosen as an organic solvent to suspend AgNPs for its miscibility with a cell medium. The obtained data showed that the antibacterial efficacy of AgNPs was retained even when AgNPs were rendered suitable for the dispersion in oil. AgNPs exhibited the same concentration-dependent effect even if administered in an organic solution (Figure 5).

\section{Cellular cytotoxicity of AgNPs}

An MTT assay was performed to evaluate the toxicity of AgNPs on murine fibroblasts (3T3-L1 cell line). Tests were performed at the same AgNPs antibacterial concentrations selected in the previous experiments with Gram-positive and Gram-negative bacteria. The medium chosen for the cytotoxicity assay was DMEM, in accordance with the NP stability.

Water- or THF-suspended AgNPs were incubated at effective antimicrobial concentrations with 3T3-L1 murine 


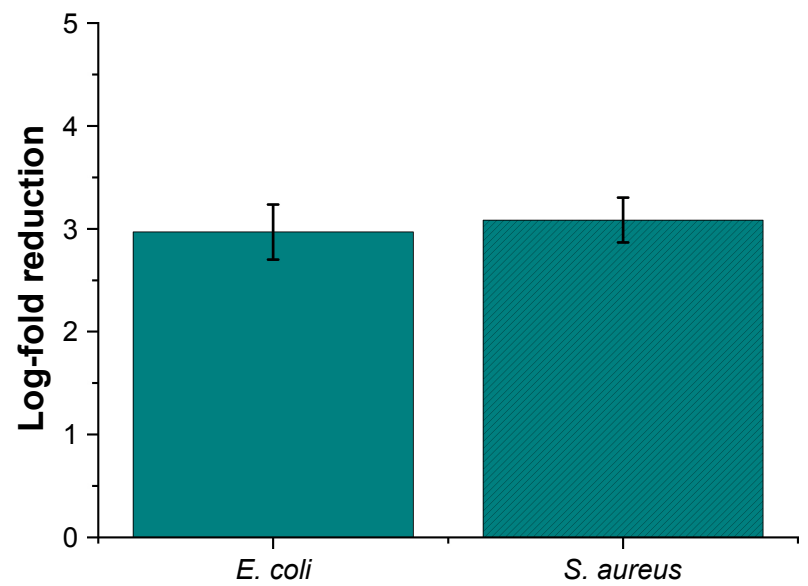

Figure 5 Antibacterial activity of AgNPs after the phase transfer, suspended in THF in Escherichia coli MGI665 (0.54 ng/mL silver content) and in Staphylococcus aureus ( $5.4 \mathrm{ng} / \mathrm{mL}$ silver content) after $2 \mathrm{~h}$.

Abbreviations: AgNPs, silver nanoparticles; THF, tetrahydrofuran.

fibroblasts. ANOVA statistical analysis showed no significant differences $(P<0.01)$ except for both tested concentrations of AgNPs in THF at $48 \mathrm{~h}$ of incubation. Observed statistical differences do not have biological significance, as cell viability percentages were 85.5 and 77.1 , respectively, for cells incubated with 10 and $1 \mathrm{ng} / \mathrm{mL}$ AgNPs, respectively. Indeed, AgNPs did not display significant cytotoxicity at the concentrations tested (Figures 6 and 7).

\section{Scanning and transmission electron microscopy analyses}

To evaluate the interaction between AgNPs and bacteria cells, both supernatants and cell pellets of $E$. coli and

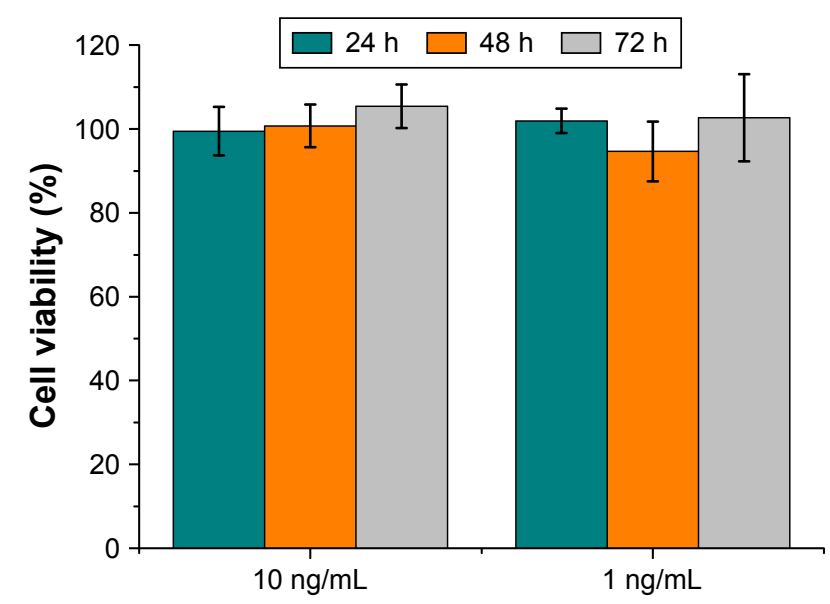

Figure 6 MTT assay performed incubating water-suspended AgNPs ( 10 and I ng/mL silver content) with murine fibroblasts 3T3-LI.

Abbreviations: AgNPs, silver nanoparticles; MTT, 3-(4,5-dimethyl-2-thiazolyl)-2,5diphenyl-2H-tetrazolium bromide.

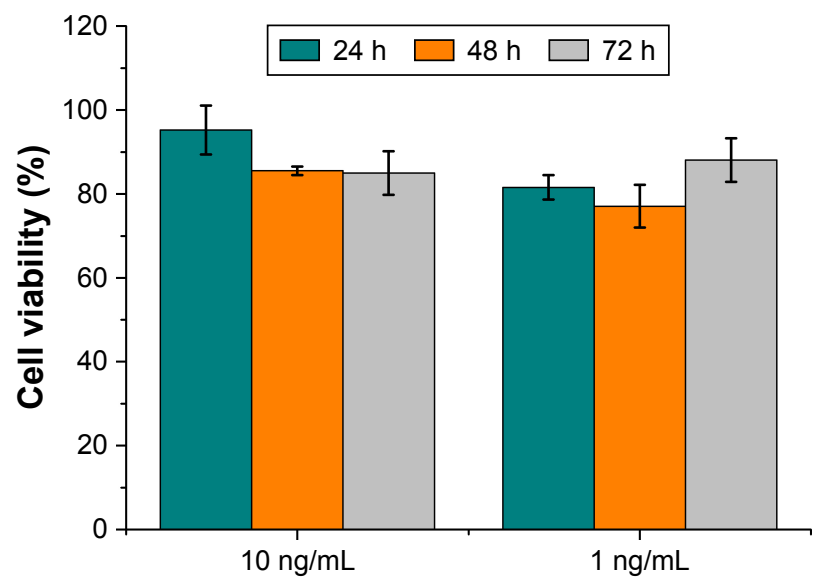

Figure 7 MTT assay performed incubating AgNPs suspended in THF ( 10 and I ng/mL silver content) with murine fibroblasts 3T3-LI.

Abbreviations: AgNPs, silver nanoparticles; MTT, 3-(4,5-dimethyl-2-thiazolyl)-2,5diphenyl-2H-tetrazolium bromide; THF, tetrahydrofuran.

$S$. aureus obtained after $2-\mathrm{h}$ incubation were visualized by TEM and SEM.

The untreated E. coli cells in the supernatant (Figure 8A and $\mathrm{C}$ ) displayed a smooth and intact surface, whereas their interaction with AgNPs (Figure 8B) caused morphological changes in the cell wall visualized as membrane corrugations. In particular, electron-dense zones surrounding the cell wall appeared in the TEM image of treated bacteria (Figure 8D). This effect was attributable to a distress effect experienced by treated cells compared with untreated ones. ${ }^{12}$

Figure 9 shows the electron microscopy images of $S$. aureus. In the control sample (Figure 9A and C), the cells were spherical in shape and intact. The treated cells (Figure 9B and D) showed some blisters on the surface in contact with AgNPs. Furthermore, numerous debris around cells were observed: this phenomenon was probably caused by cells lysis, as confirmed by analysis of cell pellets by TEM (Figure 10). In addition, only treated samples displayed the presence of mesosome-like structures (Figure 10B) in the cytoplasm. No apparent cell lysis was recovered after incubation of AgNPs with cells. This observation suggested that other mechanisms should be involved in cell damage and death, for example, membrane permeability change. ${ }^{33}$

\section{Conclusion}

In this study, uniform AgNPs having an average size of $20 \mathrm{~nm}$ and negative zeta potential with powerful antibacterial activity, suitable for pharmaceutical preparations administrable to humans and/or animals, are reported. Such NPs proved to 

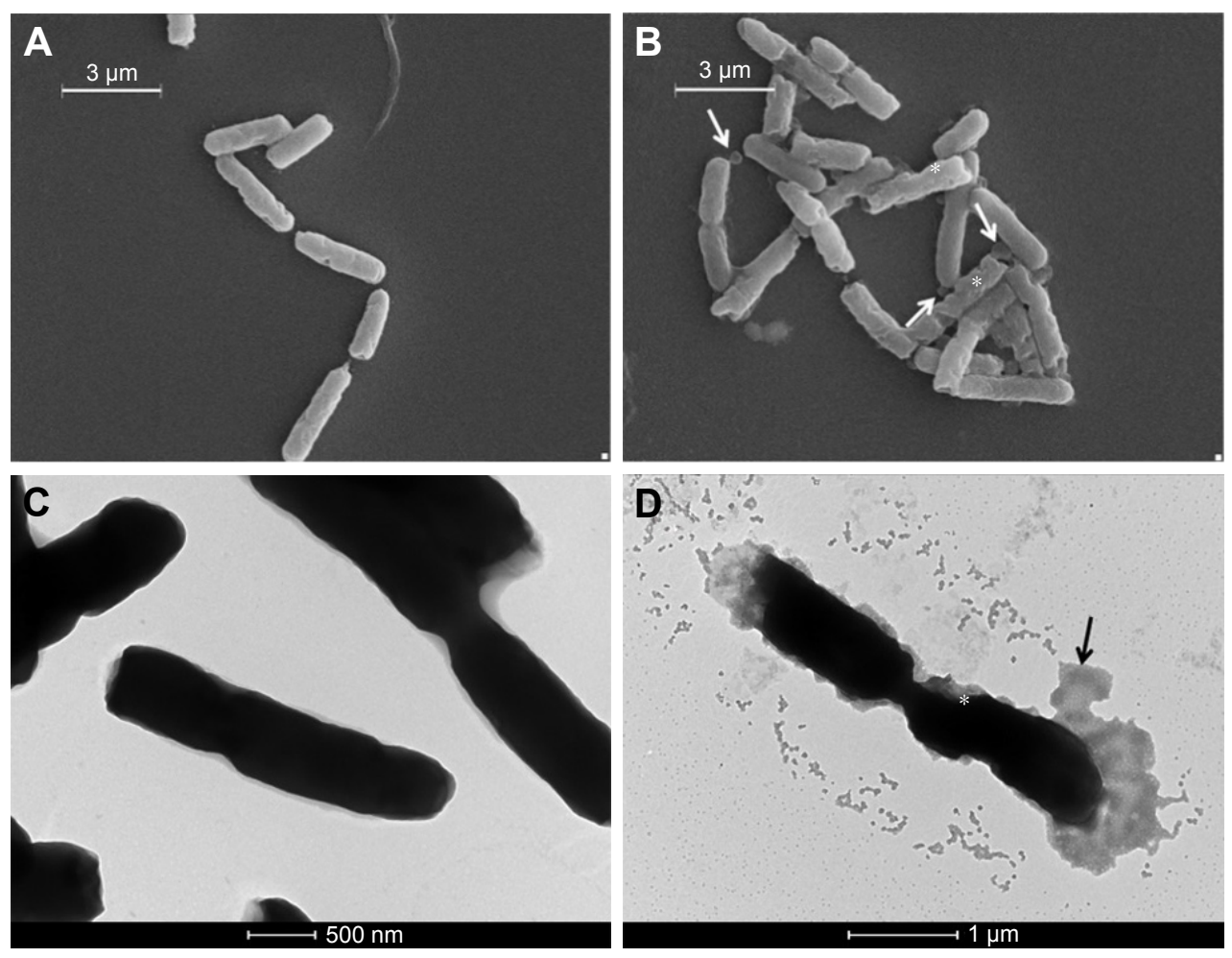

Figure 8 External morphology of untreated (A, C) and treated (B, D) Escherichia coli cells visualized with SEM (A, B) and TEM (C, D), respectively. Arrows indicate corrugations; * indicate membrane swelling (scale bars of panels A, B $=3 \mu \mathrm{m}$; panel $\mathbf{C}=500 \mathrm{~nm}$; panel $\mathbf{D}=1 \mu \mathrm{m}$ ).

Abbreviations: SEM, scanning electron microscopy; TEM, transmission electron microscopy.
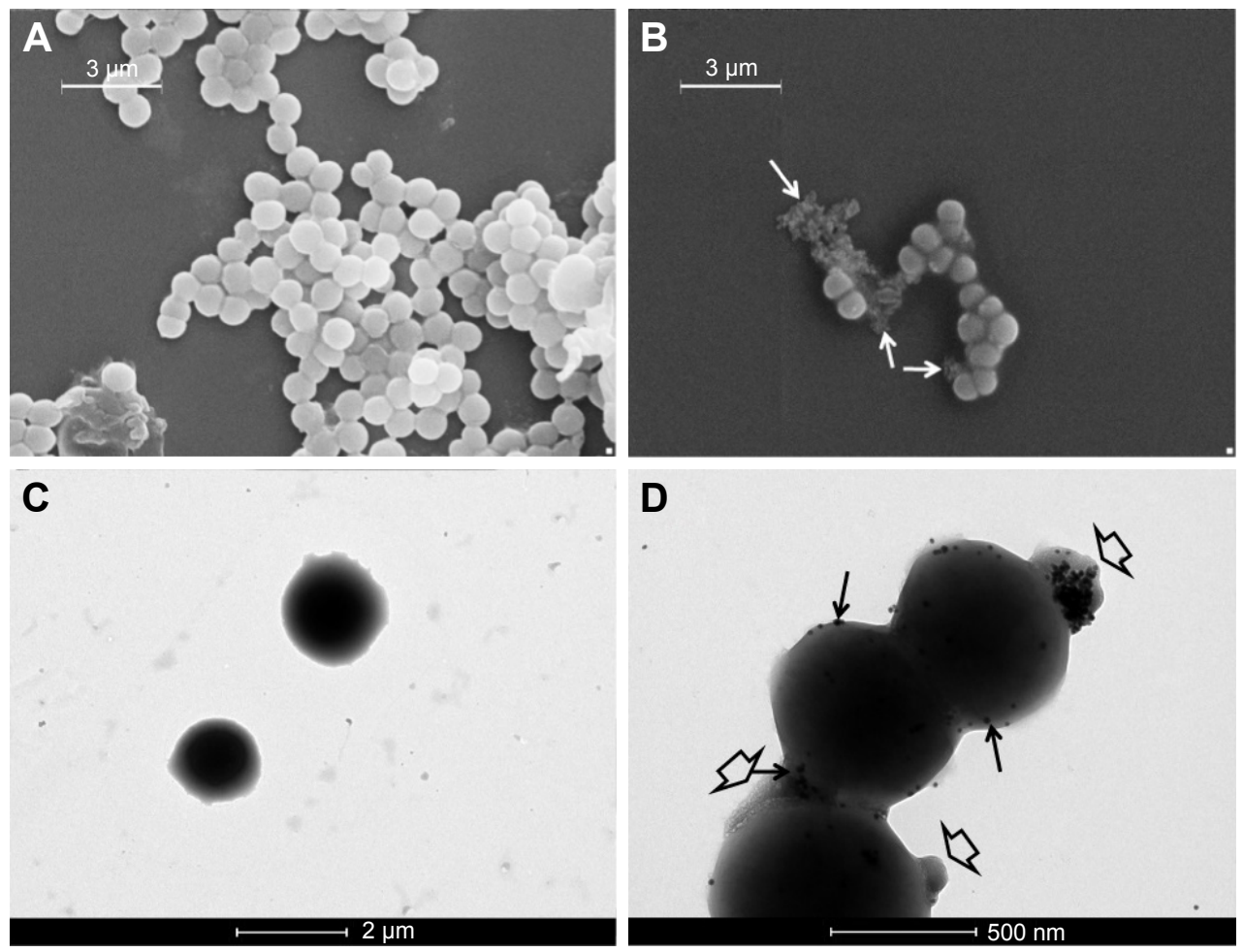

Figure 9 External morphology of untreated (A, C) and treated Staphylococcus aureus cells (B, D) visualized with SEM (A, B) and TEM (C, D), respectively. Big arrows indicate electron-dense AgNPs, whereas small arrows indicate swelling (scale bars of panels $\mathbf{A}, \mathbf{B}=3 \mu \mathrm{m}$; panel $\mathbf{C}=2 \mu \mathrm{m}$; panel $\mathbf{D}=500 \mathrm{~nm}$ ).

Abbreviations: AgNPs, silver nanoparticles; SEM, scanning electron microscopy; TEM, transmission electron microscopy. 

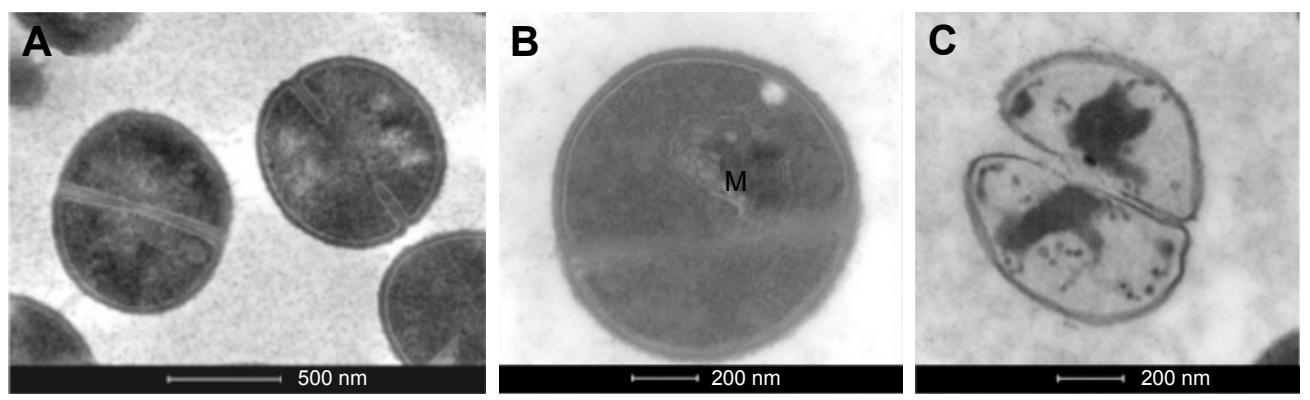

Figure 10 TEM images of untreated $(\mathbf{A})$ and treated $(\mathbf{B}, \mathbf{C})$ Staphylococcus aureus cells from the pellet. In panel $\mathbf{B}$, there is a cell that presents a mesosome-like particle (M). In panel C, a lysed cell is represented (scale bars of panel $\mathbf{A}=500 \mathrm{~nm}$; panels $\mathbf{B}, \mathbf{C}=200 \mathrm{~nm}$ ).

Abbreviation: TEM, transmission electron microscopy.

be significantly more potent compared to currently available standard AgNPs at the same concentration of silver ions. In addition, AgNPs exhibited a durable antibacterial activity and retained their efficacy both in aqueous and nonaqueous media and after freeze-drying processes. Their easy and straightforward synthesis combined with very low toxicity for eukaryotic cells make them a promising alternative to conventional additives used in food, cosmetic, nutraceutical, and pharmaceutical formulations for the conservation and preservation of their microbiological integrity.

Taking advantage of the strong stability both in aqueous and oily solutions, AgNPs can be included in liquid, semisolid, and solid formulations suitable to be administered by topical route, including intact or injured skin and mucosae, oral route, or applied on rigid or flexible surfaces that are in contact with the human or animal body.

\section{Acknowledgments}

We thank Prof Alessandra Polissi (University of MilanoBicocca) for helpful discussion and Raffaele Allevi (University of Milano) for TEM and SEM images in bacteria.

This work was supported by the following sources: Fondazione Cariplo-Regione Lombardia (Grant 2016-0886), Fondazione Regionale per la Ricerca Biomedica (FRRB) and Academic Funding Unimib 2016.

\section{Disclosure}

The authors report no conflicts of interest in this work.

\section{References}

1. Aminov RI. A brief history of the antibiotic era: lessons learned and challenges for the future. Front Microbiol. 2010;1:134.

2. D'Costa VM, King CE, Kalan L, et al. Antibiotic resistance is ancient. Nature. 2011;477(7365):457-461.

3. Lázár V, Nagy I, Spohn R, et al. Genome-wide analysis captures the determinants of the antibiotic cross-resistance interaction network. Nat Commun. 2014;5:4352.
4. Walsh C. Where will new antibiotics come from? Nat Rev Microbiol. 2003;1(1):65-70.

5. Routledge EJ, Parker J, Odum J, Ashby J, Sumpter JP. Some alkyl hydroxy benzoate preservatives (parabens) are estrogenic. Toxicol Appl Pharmacol. 1998;153(1):12-19.

6. Harvey PW, Darbre P. Endocrine disrupters and human health: could oestrogenic chemicals in body care cosmetics adversely affect breast cancer incidence in women? J Appl Toxicol. 2004;24(3):167-176.

7. Darbre PD, Aljarrah A, Miller WR, Coldham NG, Sauer MJ, Pope GS. Concentrations of parabens in human breast tumours. J Appl Toxicol. 2004;24(1):5-13.

8. Franci G, Falanga A, Galdiero S, et al. Silver nanoparticles as potential antibacterial agents. Molecules. 2015;20(5):8856-8874.

9. Rai M, Yadav A, Gade A. Silver nanoparticles as a new generation of antimicrobials. Biotechnol Adv. 2009;27(1):76-83.

10. Hajipour MJ, Fromm KM, Ashkarran AA, et al. Antibacterial properties of nanoparticles. Trends Biotechnol. 2012;30(10):499-511.

11. Ferré EC. The Many Uses of Silver. Available from: http://geology. com/articles/uses-of-silver/. Accessed March 15, 2017.

12. Jung WK, Koo HC, Kim KW, Shin S, Kim SH, Park YH. Antibacterial activity and mechanism of action of the silver ion in Staphylococcus aureus and Escherichia coli. Appl Environ Microbiol. 2008;74(7): 2171-2178.

13. Saeb ATM, Alshammari AS, Al-Brahim H, Al-Rubeaan KA. Production of silver nanoparticles with strong and stable antimicrobial activity against highly pathogenic and multidrug resistant bacteria. Sci World J. 2014;2014:704708.

14. Bastús NG, Merkoçi F, Piella J, Puntes V. Synthesis of highly monodisperse citrate-stabilized silver nanoparticles of up to $200 \mathrm{~nm}$ : kinetic control and catalytic properties. Chem Mater. 2014;26:2836-2846.

15. Tomaszewska E, Soliwoda K, Kadziola K, et al. Detection limits of DLS and UV-vis spectroscopy in characterization of polydisperse nanoparticles colloids. J Nanomaterials. 2013;2013:10.

16. Paramelle D, Sadovoy A, Gorelik S, Free P, Hobleya J, Fernig DG. A rapid method to estimate the concentration of citrate capped silver nanoparticles from UV-visible light spectra. Analyst. 2014;139(19):4855-4861.

17. Pintoa VV, Ferreira MJ, Silva R, Santosc HA, Silva F, Pereira CM. Long time effect on the stability of silver nanoparticles in aqueous medium: effect of the synthesis and storage conditions. Coll surf $A$ physicochem Eng Aspects. 2010;364(1-3):19-25.

18. Kim JS, Kuk E, Yu KN, et al. Antimicrobial effects of silver nanoparticles. Nanomedicine. 2007;3(1):95-101.

19. Elechiguerra JL, Burt JL, Morones JR, et al. Interaction of silver nanoparticles with HIV-1. J Nanobiotechnol. 2005;3:6.

20. Hwang ET, Lee JH, Chae YJ, et al. Analysis of the toxic mode of action of silver nanoparticles using stress-specific bioluminescent bacteria. Small. 2008;4(6):746-750.

21. Lok CN, Ho CM, Chen R, et al. Silver nanoparticles: partial oxidation and antibacterial activities. J Biol Inorg Chem. 2007;12(4):527-534. 
22. Wiegand I, Hilpert K, Hancock RE. Agar and broth dilution methods to determine the minimal inhibitory concentration (MIC) of antimicrobial substances. Nature Protoc. 2008;3(2):163-175.

23. Lu Z, Rong K, Li J, Yang H, Chen R. Size-dependent antibacterial activities of silver nanoparticles against oral anaerobic pathogenic bacteria. J Mater Sci Mater Med. 2013;24(6):1465-1471.

24. Akram Raza M, Kanwal Z, Rauf A, Nasim Sabri A, Riaz S, Naseem S. Size- and shape-dependent antibacterial studies of silver nanoparticles synthesized by wet chemical routes. Nanomaterials. 2016;6(4):74.

25. Agnihotri S, Mukherjiabc S, Mukherj S. Size-controlled silver nanoparticles synthesized over the range 5-100 $\mathrm{nm}$ using the same protocol and their antibacterial efficacy. RSC Adv. 2014;4:3974-3983.

26. Thill A, Zeyons O, Spalla O, et al. Cytotoxicity of $\mathrm{CeO}_{2}$ nanoparticles for Escherichia coli. Physico-chemical insight of the cytotoxicity mechanism. Environ Sci Technol. 2006;40(19):6151-6156.

27. Soenen SJ, Rivera-Gil P, Montenegro JM, Parak WJ, De Smedt SJ, Braeckmans K. Cellular toxicity of inorganic nanoparticles: common aspects and guidelines for improved nanotoxicity evaluation. Nano Today. 2011;6(5):446-465.
28. Nel AE, Mädler L, Velegol D, et al. Understanding biophysicochemical interactions at the nano-bio interface. Nat Mater. 2009;8(7):543-557.

29. Samberg ME, Orndorff PE, Monteiro-Riviere NA. Antibacterial efficacy of silver nanoparticles of different sizes, surface conditions and synthesis methods. Nanotoxicology. 2011;5(2):244-253.

30. Li WR, Xie XB, Shi QS, Duan SS, Ouyang YS, Chen YB. Antibacterial effect of silver nanoparticles on Staphylococcus aureus. Biometals. 2011;24(1):135-141.

31. Yang J, Lee JY, Too HP. A general phase transfer protocol for synthesizing alkylamine-stabilized nanoparticles of noble metals. Anal Chim Acta. 2007;588(1):34-41.

32. Fayaz AM, Balaji K, Girilal M, Yadav R, Kalaichelvan PT, Venketesan R. Biogenic synthesis of silver nanoparticles and their synergistic effect with antibiotics: a study against gram-positive and gramnegative bacteria. Nanomedicine. 2010;6(1):103-109.

33. Choi O, Deng KK, Kim NJ, Ross L, Surampalli RY, Hu Z. The inhibitory effects of silver nanoparticles, silver ions, and silver chloride colloids on microbial growth. Water Res. 2008;42(12):3066-3074. 


\section{Supplementary materials}

Table SI Silver nanoparticles characterization

\begin{tabular}{llll}
\hline Sample & Effective diameter (TEM analysis, $\mathbf{n m})$ & Hydrodynamic diameter (DLS analysis, $\mathbf{n m})$ & $\zeta$ potential $(\mathbf{m V})$ \\
\hline 1 & $19.3 \pm 5.6$ & $41.4 \pm 2.0$ & $21.6 \pm 1.8$ \\
2 & $17.7 \pm 6.9$ & $41.5 \pm 1.8$ & $23.5 \pm 2.9$ \\
3 & $20.9 \pm 4.7$ & $42.3 \pm 4.7$ & $18.3 \pm 1.9$ \\
\hline
\end{tabular}

Note: The results are expressed as mean \pm standard deviation of three measurements. Abbreviations: DLS, dynamic light scattering; TEM, transmission electron microscopy.

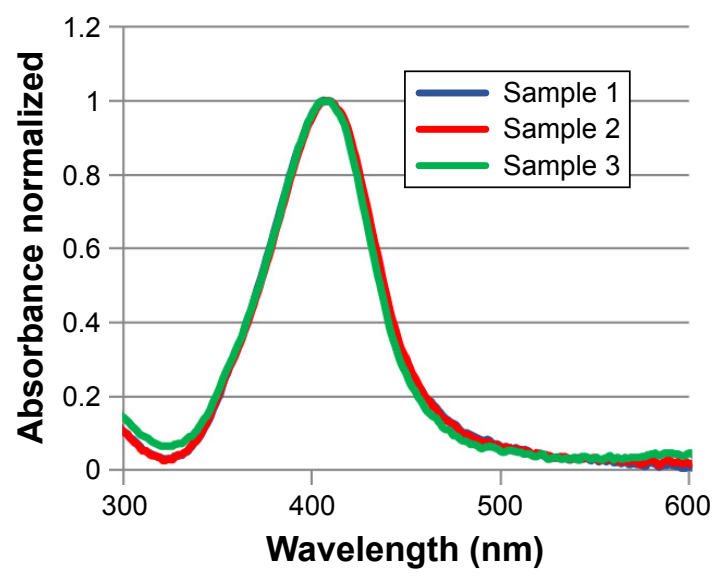

Figure SI Plasmon band position of three samples of AgNPs by UV-vis absorption spectroscopy. Abbreviations: AgNPs, silver nanoparticles; UV-vis, ultraviolet-visible.
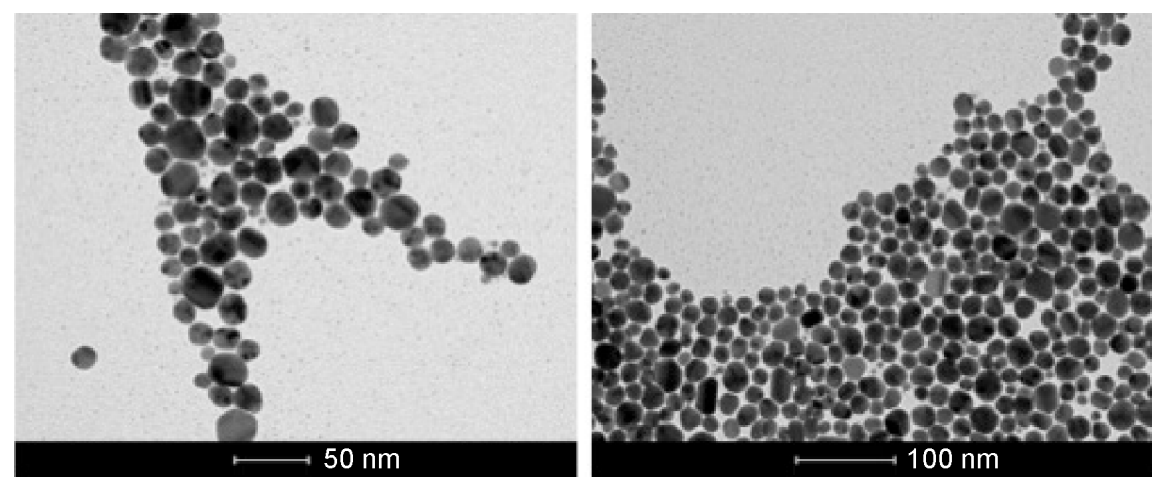

Figure S2 TEM images of AgNPs suspended in water, scale bar: $50 \mathrm{~nm}$ (left) and $100 \mathrm{~nm}$ (right).

Abbreviations: AgNPs, silver nanoparticles; TEM, transmission electron microscopy. 
A
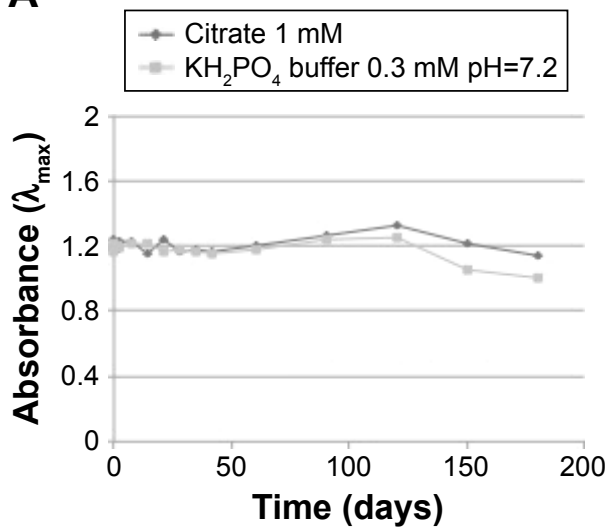

B
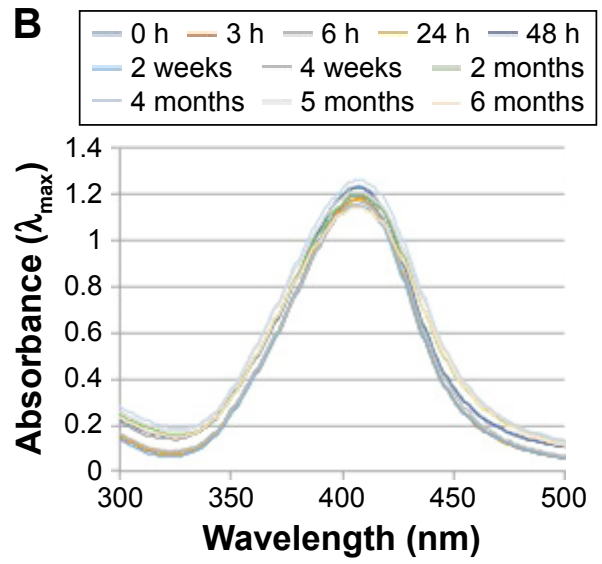

Figure S3 Long-term stability of AgNPs in citrate buffer I mM and phosphate buffer $0.3 \mathrm{mM}(\mathrm{pH} 7.2)(\mathbf{A})$ expressed as absorbance at $\lambda_{\text {max }}$ variations as function of time; plasmon band position of AgNPs by UV-vis absorption spectroscopy (B). Abbreviations: AgNPs, silver nanoparticles; UV-vis, ultraviolet-visible.
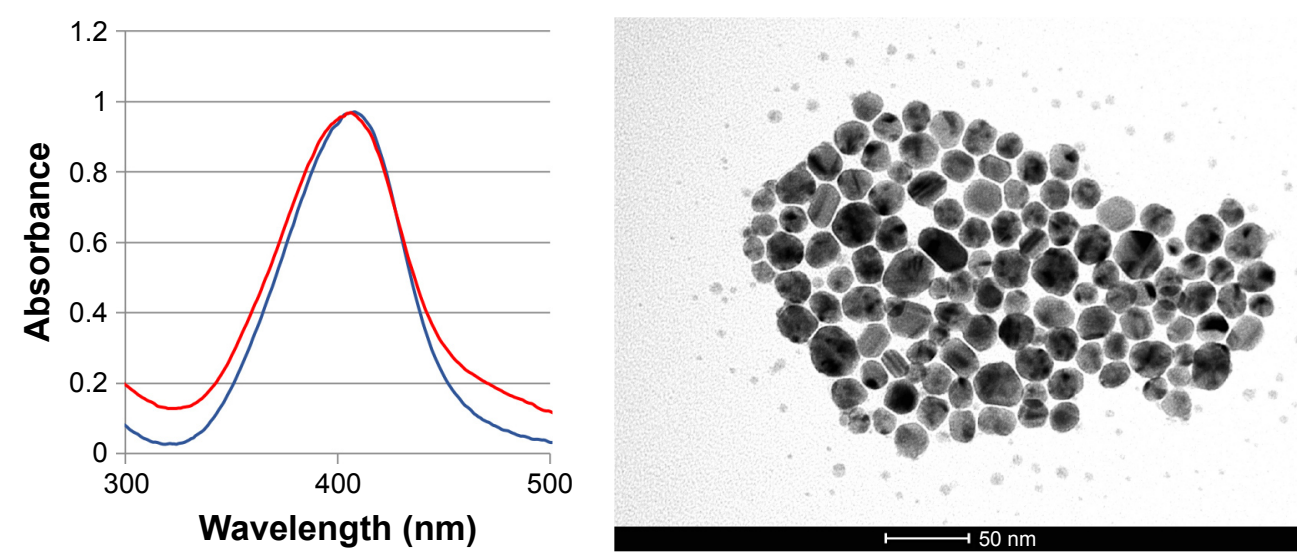

Figure S4 AgNPs stability evaluated by UV-vis spectroscopy in citrate I mM before (red line) and after (blue line) the lyophilization (left). TEM image of lyophilized AgNPs (right).

Abbreviations: AgNPs, silver nanoparticles; TEM, transmission electron microscopy; UV-vis, ultraviolet-visible.

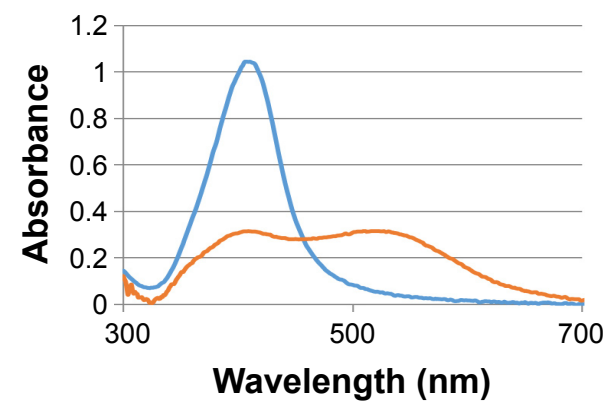

Figure S5 AgNPs suspended in bacteria nutrient broth (orange line) and in sodium citrate I mM solution (blue line). In the first case, as broader peak shows, nanoparticles aggregation occurs.

Abbreviation: AgNPs, silver nanoparticles. 

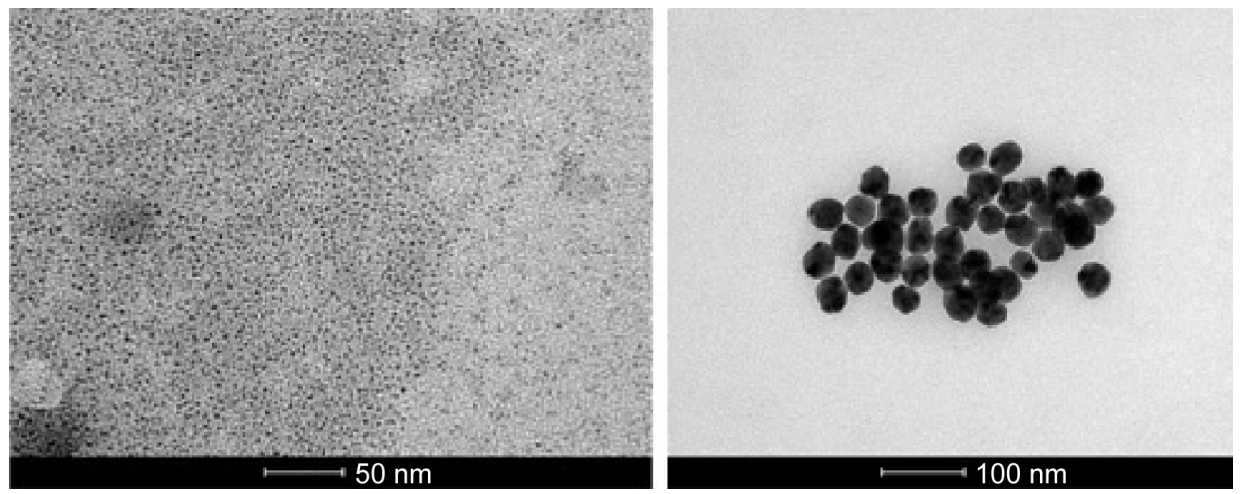

Figure S6 TEM images of CSNPs, scale bar: $50 \mathrm{~nm}$ (left) and SNPs scale bar: $100 \mathrm{~nm}$ (right).

Abbreviations: CSNPs, colloidal silver nanoparticles; SNPs, silver nanoparticles; TEM, transmission electron microscopy.
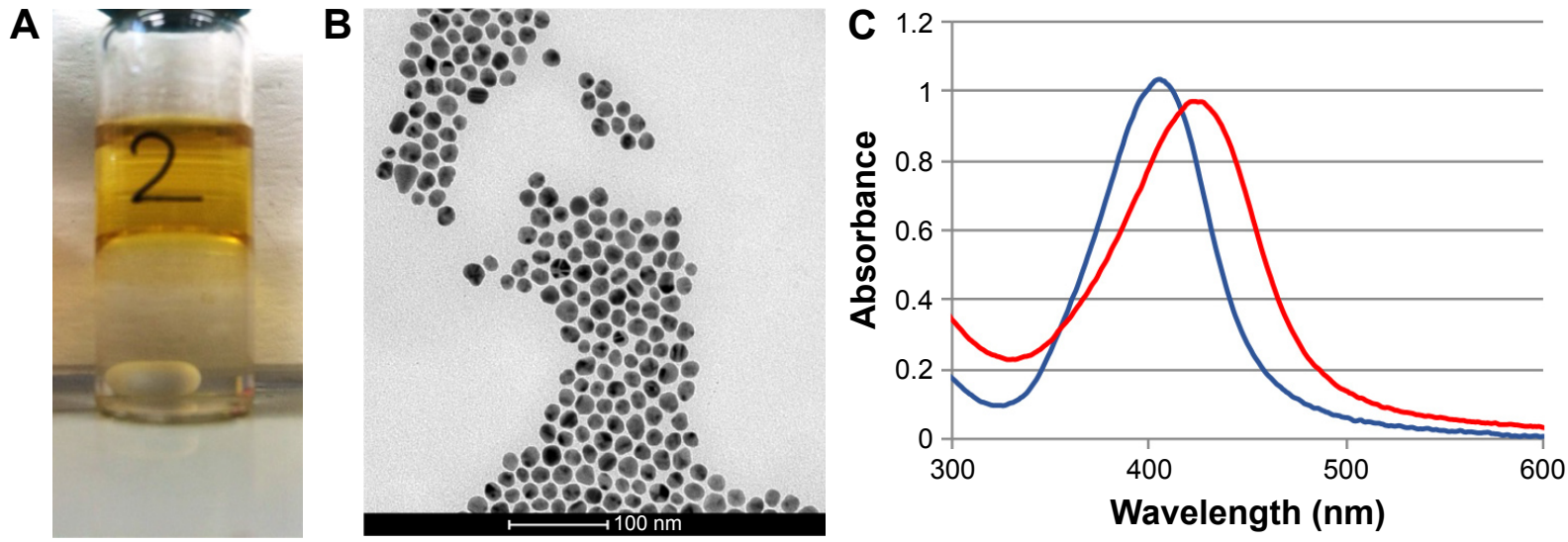

Figure S7 AgNPs in toluene characterization.

Notes: (A) AgNPs phase transfer in toluene; (B) TEM image of AgNPs in toluene; (C) AgNPs stability in water (blue line) after the phase transfer in toluene (red line). Differences of UV-vis spectra may be due to surface binding of octadecylamine and increasing in the refractive index from water (refractive index, $\mathrm{n}=\mathrm{I}$.33) to toluene $(\mathrm{n}=\mathrm{I} .50)$.

Abbreviations: AgNPs, silver nanoparticles; TEM, transmission electron microscopy; UV-vis, ultraviolet-visible.

\section{Publish your work in this journal}

The International Journal of Nanomedicine is an international, peerreviewed journal focusing on the application of nanotechnology in diagnostics, therapeutics, and drug delivery systems throughout the biomedical field. This journal is indexed on PubMed Central, MedLine, CAS, SciSearch ${ }^{\circledR}$, Current Contents ${ }^{\circledR} /$ Clinical Medicine,
Journal Citation Reports/Science Edition, EMBase, Scopus and the Elsevier Bibliographic databases. The manuscript management system is completely online and includes a very quick and fair peer-review system, which is all easy to use. Visit http://www.dovepress.com/ testimonials.php to read real quotes from published authors. 